\title{
REPORT OF THE TREATMENT OF EXPERIMENTAL FAT EMBOLISM WITH HEPARIN
}

\author{
A. M. N. Gardner, Oxford, England \\ Division of Surgery, Radcliffe Infirmary, Oxford \\ and \\ M. H. M. Harrison, London, ENGLAND \\ Formerly of the Nuffield Orthopaedic Centre, Oxford
}

The clinical manifestations of fat embolism may be seen quite frequently by those responsible for the treatment of the injured, and the condition is diagnosed even more commonly by pathologists making special search for it in persons who have died after injury (Robb-Smith 1941). As Harris (1955) has recently stressed, many problems concerning the source of the fat and the cause of its appearance remain undecided, and the surgeon is frustrated by the lack of any specific prophylactic or therapeutic measure. Hahn (1943) reported that heparin had the effect in vivo of "clearing" lipaemic plasma-that is, of rendering plasma which had become milky and opalescent after a fatty meal again translucent, and it seemed possible that heparin might thus be of value in the treatment of fat embolism. If the chylomicra of lipaemic plasma are so effectively lysed (French, Robinson and Florey 1953), might not the fat particles present in the blood in fat embolism be similarly removed, thereby decreasing the risk of continuing or repeated visceral infarction? This was the rationale for a study of the effects of heparin in experimental fat embolism.

The results of such an investigation are presented in this report, and they suggest that a clinical trial of heparin in human fat embolism is not only unwarranted, but might be dangerous.

\section{MATERIALS AND METHODS}

Witzar strain rats were used for the experiments, and embolism was produced by injecting the fat into the femoral vein exposed at the groin under Nembutal anaesthesia. Each injection was given evenly during one minute.

With the object of simulating as closely as possible naturally occurring fat embolism, homogenous fat was used: it was prepared as follows.

The perirenal and epididymal fat pads of freshly killed rats were stored in absolute ethyl alcohol; anaesthetic ether ( 2 pints to 1 of alcohol) was then added and the tissue was minced up in a Waring blender. After filtration the alcohol and ether were evaporated off under reduced pressure, the fat was brought up to 100 degrees Centigrade to coagulate any tissue protein still present, and it was filtered again and set up in glass ampoules. These were sealed after autoclaving for fifteen minutes at five pounds per square inch.

The minimal lethal dose (M.L.D.) of the fat varied slightly from batch to batch and the dosage used in the experiments was accordingly varied with each batch to keep the fatality rate fairly constant.

In the first series of experiments reported below heparin (" Liquemin" brand (Roche) $5,000 \mathrm{i}$.u./millilitre) was injected into the femoral vein in a dose of approximately 0.6 milligrams per 100 grammes body weight either immediately before or immediately after the fat had been given. In the second series heparin was administered by the combined intraperitoneal ( 0.6 milligrams per 100 grammes) and intramuscular routes (Heparin Retard (Boots) 1.2 milligrams per 100 grammes). Clotting times were estimated to confirm that the intraperitoneal heparin had been absorbed. 
The experiments were controlled as follows. Fat embolism was induced in a series of rats, but heparin was given to only half of the animals. The time elapsing before death, if this occurred, was recorded and a post-mortem examination was performed on all animals that died. The groups of figures depicting survival times, presented below, were each compiled from a series of such experiments, each fully controlled, but not performed on the same occasion.

\section{RESULTS}

Fat embolism-In suitable dosage the intravenous administration of homogenous fat by the technique described above usually caused death one to twelve hours after the injection of the fat. Deaths occurring instantaneously or more than thirty-six hours after injection were rare; the former were ascribed to shock, the latter were often associated with clot retention in the bladder from haematuria. It was not uncommon to detect signs highly suggestive of cerebral fat embolism (ocular palsies, ataxia, fits, hemiparesis) in animals surviving for more than a few hours after injection. Petechial haemorrhages were common, particularly in the thymus of animals dying late.

Post-mortem examination showed dilation of the right side of the heart and secondary pleural effusions. Microscopically the intrapulmonary vessels were seen to be laden with fat and it seemed likely that death was due to anoxia following right heart failure.

The effect of heparin on fat embolism-The effects of administering heparin together with an intravenous dose of 0.16 millilitre fat per 100 grammes body weight are shown in Figure 1 and Table I. Table II shows the results in a further similar series, also in the form of survival times. From these it will be seen that heparin greatly accelerates the mortality from fat embolism in the first four hours after its

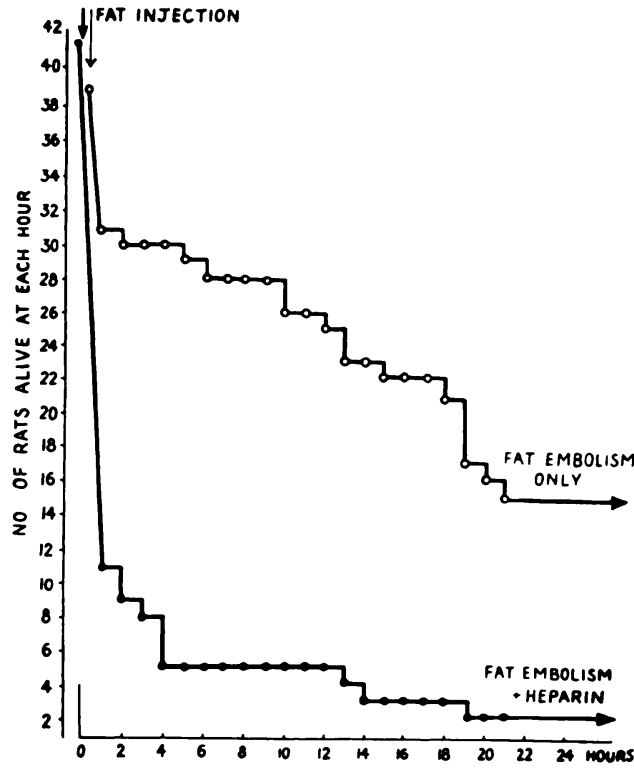

Fig. 1

Graph showing the effects of heparin in experimental fat embolism (solid circles) compared with a control group of animals which suffered fat embolism alone (clear circles). Details of dosage of fat and heparin as stated in text. induction, and also increases the total mortality over an arbitrary observation period of forty-eight hours. Heparin alone, in three times the doses used in these experiments, had no lethal effect on ten rats which were given $0 \cdot 1$ millilitre intravenously.

There were no macroscopic or microscopic differences observed at post-mortem examination between the animals that died after fat embolism alone and those that had also received heparin. More particularly, we were unable to detect haemorrhages in viscera or tissue spaces from giving heparin to the latter group of animals.

\section{DISCUSSION}

It has been shown that the administration of heparin to rats in which homogenous fat embolism has been experimentally induced causes a great acceleration of mortality in the early stages after the initial embolism and also increases the ultimate mortality. Post-mortem examination of the cadavera of the rats and microscopy of their tissues reveals that the deaths promoted by heparin are not due to internal haemorrhage, which theoretically might have been caused by the best known of the properties of heparin, the anti-coagulant effect.

vol. 39 B, No. 3, AUGUST 1957 
It is certain that many features of the fat embolism induced in these experiments differ from those that obtain in man after injury. Nevertheless it seems likely that heparin would also be harmful in human fat embolism, and this report is occasioned partly by this conclusion, lest others, reading the papers that aroused our interest in the subject, might be tempted to

TABLE I

Time-table of Deaths in Rats Suffering Experimental Fat Embolism. Fat dosage 0.16 millilitres per 100 grammes body weight. This shows that heparin both accelerates death and increases the number of deaths.

\begin{tabular}{|ccc|}
\hline Time & \multicolumn{2}{c|}{ Deaths } \\
\hline 0 to 2 hours & $\begin{array}{c}\text { Fat embolism } \\
\text { alone }\end{array}$ & $\begin{array}{c}\text { Fat embolism } \\
\text { plus heparin }\end{array}$ \\
$2+$ to 12 hours & 9 & 32 \\
$12+$ to 48 hours & 5 & 4 \\
\hline Number of rats surviving & 10 & 3 \\
\hline Total number of rats . & 15 & 2 \\
\hline Percentage of rats surviving & 39 per cent & 5 per cent \\
\hline
\end{tabular}

try the effect of the drug on such patients. At the outset of this work we felt that heparin therapy in human fat embolism, apart from the controllable risks of haemorrhage, could at the very worst "do no harm "; it now appears that this premise may be incorrect.

Further experiments not detailed in this report have shown that this effect of heparin is not limited to fat embolism, but is similarly exerted in the presence of emboli of entirely

TABLE II

Death Time-table in an Experiment with Rats like that in Table I, except that heparin was given both intraperitoneally and intramuscularly. Fat dosage $0 \cdot 18$ millilitres per 100 grammes body weight.

\begin{tabular}{|ccc|}
\hline Time & \multicolumn{2}{c|}{ Deaths } \\
\hline 0 to 2 hours & $\begin{array}{c}\text { Fat embolism } \\
\text { alone }\end{array}$ & $\begin{array}{c}\text { Fat embolism } \\
\text { plus heparin }\end{array}$ \\
\hline $2+$ to 12 hours & 4 & 13 \\
$12+$ to 48 hours & 13 & 17 \\
\hline Number of rats surviving & 11 & 1 \\
\hline Total number of rats . & 9 & 4 \\
\hline Percentage of rats surviving & 24 per cent & 11 per cent \\
\hline
\end{tabular}

different physico-chemical nature. These experiments with heparin and embolisms with other oils and gases, together with electro-phoretic studies, indicated that the action of heparin was on the protein at the fat-plasma or the oil-plasma interface: this will be reported in detail by one of us (A. M. N. G.) elsewhere. 


\section{SUMMARY}

1. Reports of the lipaemia-clearing effect of heparin suggested that this drug might be of therapeutic value in fat embolism.

2. In an experimental trial with rats, heparin was found both to accelerate death and to increase the number of deaths after fat embolism.

3. It is accordingly concluded that a clinical trial of heparin in human fat embolism would not be warranted.

We would like to express our thanks to Professor J. Trueta and Dr A. H. T. Robb-Smith for their guidance and for defraying the expenses of this investigation, and to Dr R. Sladden for his assistance in the microscopic examination of the post-mortem material. The help given by $\mathrm{Mr} \mathrm{W}$. Charles in the performance of the experiments was invaluable.

\section{REFERENCES}

French, J. E., Robinson, D. S., and Florey, H. W. (1953): The Effect of the Intravenous Injection of Heparin on the Interaction of Chyle and Plasma in the Rat. Quarterly Journal of Experimental Physiology, 38, 101. HAHN, P. F. (1943): Abolishment of Alimentary lipemia Following Injection of Heparin. Science, 98, 19. HARRIS, R. I. (1955): Personal communication.

RobB-Smith, A. H. T. (1941): Pulmonary Fat-embolism. Lancet, i, 135. 